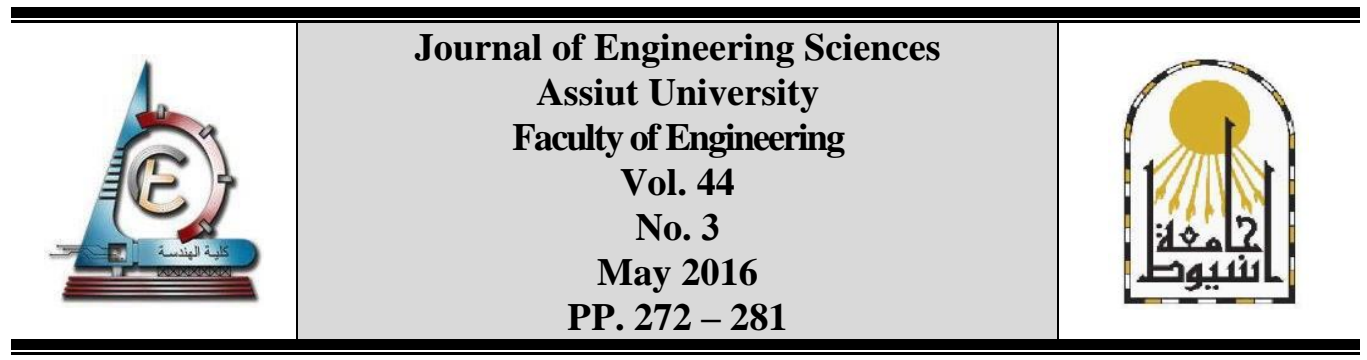

\title{
APPLICATION OF AGE OF AIR OF INDOOR ENVIRONMENTS AS A PROMISING INDEX TO EVALUATE THE OUTDOOR AIR QUALITY USING CFD SIMULATIONS
}

\author{
Mahmoud Bady \\ Mechanical Engineering Department, Assiut University, Assiut, Egypt \\ Department of Energy Resources Engineering, E-JUST, Alexandria, Egypt \\ Email:mahmoud.bady@ejust.edu.eg
}

Received 14 March 2016; Accepted 12 April 2016

\begin{abstract}
In this work, CFD simulations were performed to assess the air quality within urban domains through applying one of the ventilation indices for enclosed domains. The index is the Age of Air (AoA), which represents the time consumed by the applied wind to reach a particular point after it enters the considered study domain. The study presents an example of evaluating the air quality of urban areas in terms of AoA. The estimated values of the index were compared to the values of another index which is the purging flow rate. The results of this work confirm that; AoA index of indoor environments is a promising index for the air quality assessment of urban domains as well.
\end{abstract}

Key-words: Age of air, air quality, CFD, urban ventilation, ventilation efficiency

\section{SYMBOLS}

c Pollutant concentration $(\mathrm{kg} / \mathrm{kg})$

$C_{\mu} \quad$ Constant

$D \quad$ Stack exit diameter $(\mathrm{m})$

$d x d y d z \quad$ Volume of cell $i\left(\mathrm{~m}^{3}\right)$

I Turbulent intensity of the applied flow (\%)

$K \quad$ Turbulent diffusivity of pollutant $(\mathrm{kg} / \mathrm{m} / \mathrm{s})$,

$K \quad$ Turbulent kinetic energy $\left(\mathrm{m}^{2} / \mathrm{s}^{2}\right)$

$S \quad$ Pollutant source strength $\left(\mathrm{kg} / \mathrm{m}^{3} / \mathrm{s}\right)$

$u_{i} \quad$ Cartesian components of the velocity $(\mathrm{m} / \mathrm{s})$

Vol Domain volume $\left(\mathrm{m}^{3}\right)$

$x_{i} \quad$ Cartesian coordinates $(\mathrm{m})$

$P \quad$ Air density $\left(\mathrm{kg} / \mathrm{m}^{3}\right)$

$\tau_{p} \quad$ Local mean age of air (s)

$\varepsilon \quad$ The turbulent dissipation rate $\left(\mathrm{m}^{2} / \mathrm{s}^{3}\right)$

\section{Introduction}

In the design of new building arrays, it is important to assess the ventilation performance of urban domains quantitatively and qualitatively. Spatial and temporal 
distributions of air pollutants are the main players in such assessment. Although wind tunnel experiments represent one of the tools used to quantify the pollutant diffusion characteristics within a study domain, numerical analysis is considered more powerful in this regard. This can be attributed to the difficulty of employing wind tunnel experiments to measure the appropriate indices of ventilation. The problem is that; the needed data for evaluating these indices is hard to be attained in wind tunnel experiments.

Many researchers have dealt with the distribution of pollutants within urban areas. Some of these studies were concerned with the air quality investigation of street canyons [1-3] and densely populated areas [4-5]. However, in the present study, it is believed that; the determination of pollutant concentration alone is insufficient to reflect the complete image of the air quality in urban domains. Other parameters are thought to be important when evaluating the air quality of urban domains in addition to concentration.

There are different indices, which are used to assess the air quality of a room or a domain located within an indoor environment. These indices are purging flow rate [6], visitation frequency [7] and the six indices SVE1-6 [8]. It was believed that; the ventilation indices of indoor domains are also effective in evaluating the air quality of urban domains, as reported by Bady et al. [6] and Huang et al. [9].

Among many air quality indices of indoor environments, the Age of Air (AoA) index was selected to carry out the present investigation. The AoA concept was proposed by Sandberg [8] to examine ventilation efficiency using the local mean age of air in enclosed domains. It was used to evaluate fresh air distribution as well as contamination evacuation, respectively. The objective of this study is to investigate the effectiveness of using the age of air index as a parameter for evaluating the ventilation efficiency of urban domains.

Currently, experimental methods for measuring the "age of air" have some difficulties, especially concerning the required data and for uncertainties due to tracer-gas instability. The feasible approach for evaluating the age of air index is through CFD simulations.

\section{The index of "age of air"}

Local Mean Age of Air (LMA) is one of the most important parameters when ventilation efficiency in an enclosed domain is considered [7]. At an arbitrary point $\mathrm{P}$ of the closed domain, LMA is defined as the average time that is needed for air to reach the point $\mathrm{P}$ since it entered the room. In outdoor environments, it is thought that; this concept can be used to study how the incident wind ventilates an urban domain since the age of air is based mainly on the average spatial distribution characteristics of pollutants (tracer diffusion).

Age of air can be evaluated only through CFD simulations. It is not easy to use wind tunnel experiments to measure any of the ventilation indices [6]. In order to be independent of the pollution source location within the domain, a uniform generation rate is required. Such condition is impossible to satisfy using wind tunnel experiments till now. Additionally, many difficulties reduce the chance of achieving acceptable experimental results. These difficulties include [6]:

1) The symmetrical flow condition of the wind is difficult to satisfy in wind tunnel experiments.

2) Assuming steady wind flow is impractical.

3) The estimated boundary layer profile is quite simple compared with reality.

4) Fluctuations in the incident wind direction. 
Such difficulties make the process of estimating the mean age of air experimentally difficult. However, many experimental trials were conducted by the author of this study to estimate the indices of ventilation experimentally. Unfortunately; the results of these experimental trials were not readily usable [6].

The age of air is estimated using passive pollutant, which means the flow field, is not influenced by the pollutants. This technique enables us to calculate the flow field first and then use this calculated flow field in estimating the required index [6]. Accordingly, the first step is to solve the flow field. Then, a uniform generation rate within the study domain is applied to be independent of the source location within the domain. With the calculated flow field, the pollutant concentration is calculated by solution of the 3-D steady state convectivediffusion equation. The coordinate-free vector form of this equation is [10]:

$$
\operatorname{div}\left(\rho u_{i} c\right)=\operatorname{div}(K \operatorname{grad} c)+S
$$

The local mean age of air $\tau_{p}$ at any cell $i$ within the domain is [11]:

$$
\tau_{p}=\frac{\rho c_{i}}{S}
$$

Then, the average age of air within the whole domain is:

$$
\bar{\tau}_{p}=\frac{\int_{V o l} \tau_{p} d x d y d z}{V o l}
$$

To compare the performance of age of air in the air quality assessment of urban domains, the purging flow rate $(P F R)$ index is used. Such index represents the net rate by which the pollutants are flushed out of the domain. $P F R$ reflects the capacity at which the wind removes the pollutant from the domain. The following equation is used to calculate PFR [6]:

$$
P F R=\frac{S \times V o l}{c \times \rho}
$$

\section{Example of applying age of air to evaluate the air quality of urban domains}

An example is presented here to assess the air quality of urban domains in terms of the age of air. The campus of Egypt-Japan University of Science and Technology (E-JUST) is adopted to carry out the study. E-JUST campus is located in the new Borg El-Arab City, near Alexandria, Egypt. The campus -as shown in Fig. 1- consists of fourteen buildings. Each building has a height of $17 \mathrm{~m}$, and its geometry and dimensions are illustrated in Fig. 2. The campus building array is making an angle of $37^{\circ}$ with the north direction.

\section{CFD simulation}

Numerical simulations of the wind environment were performed using the CFD code STAR-CCM+, based on a finite-volume discretization method. The standard k- $\varepsilon$ model was adopted to simulate the turbulence effects. The steady-state condition was applied to estimate a steady wind flow field. The second order upwind scheme was used in the convective term, and the central difference scheme was used for the diffusion terms. The first order upwind 
scheme was considered in solving the scalar transport equation, and the SIMPLE algorithm was employed to conserve mass and couple the pressure to the velocity field.

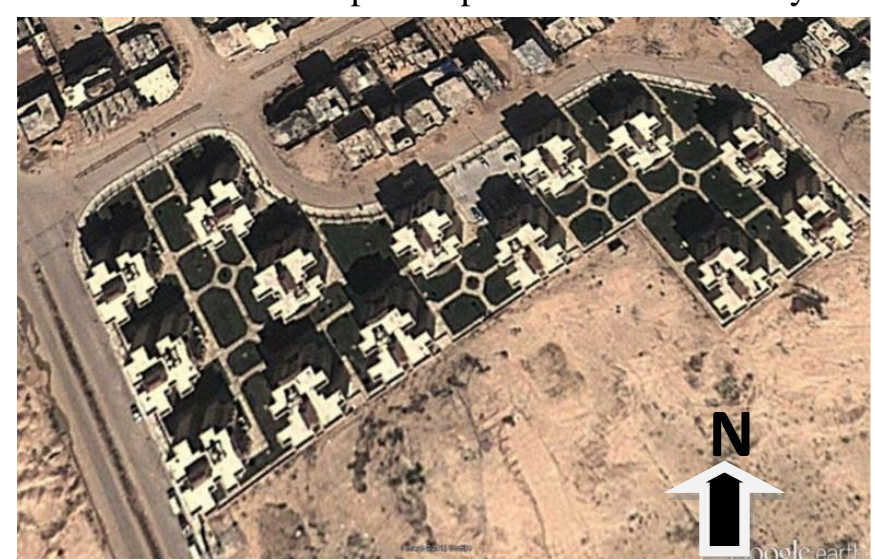

Fig. 1. Geometry of E-JUST campus

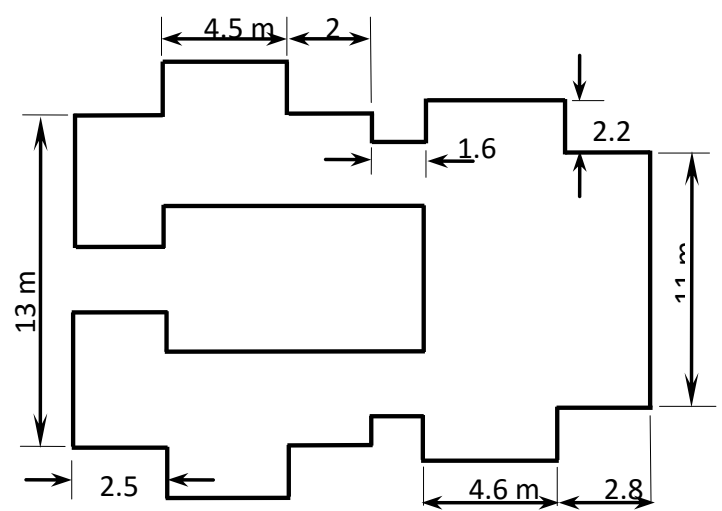

Fig. 2. Geometry and dimensions of one building of E-JUST array

At the inlet, a constant flux layer was assumed for the turbulent energy $(k)$ as given by Equ. (5). The turbulent intensity ( $I$ ) was assumed to be $10 \%$ of the inflow wind velocity at a standard height $\left(z_{o}\right)$ of $74.6 \mathrm{~m}$. The turbulent dissipation rate is calculated according to Equ. (6), which arises from assuming local equilibrium [12].

The incident wind velocity in Alexandria city makes an angle of $37^{\circ}$ with the direction of the building array. Figure 3 shows the wind rose of the city, which is drawn, based on the mean hourly measured data over a period of thirteen months ranging from January 2011 to January 2012.

$$
\begin{gathered}
k \cong 1.5(u \times I)^{2} \\
\varepsilon \cong C_{\mu}^{1 / 2} \times k \times \frac{\partial u}{\partial z}
\end{gathered}
$$

Concerning the top and side boundaries, free slip condition was applied. The logarithmic law was implemented to the boundaries at ground level and for building walls as smooth surfaces. The von-Neumann zero normal derivatives had been applied to the downwind boundary. 


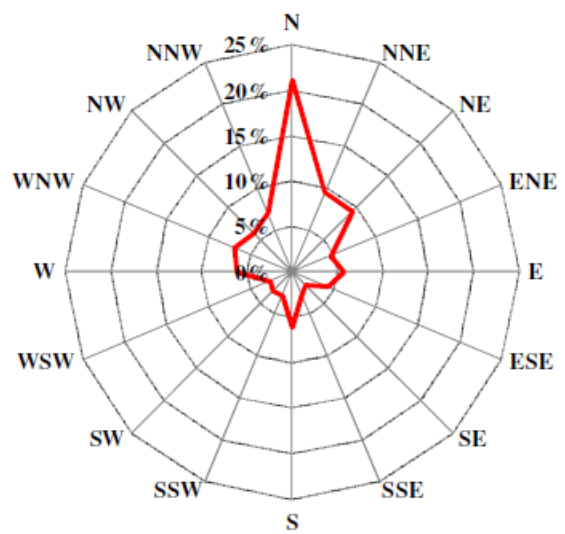

Fig. 3. Wind rose of Alexandria (averaged over 1 hour)

Fine meshes had been applied near the walls of the buildings, and coarse ones were used far from them, as shown in Fig. 4. This technique was applied to ensure a proper resolution of the boundary layers in the study domain. Table 1 summarizes the parameters that used in the numerical simulations and the applied boundary conditions.

Age of air index can be calculated using the particle-tracking method based on Large Eddy Simulation (LES) or through the passive pollutant flux method based on the ReynoldsAveraged Navier-Stokes (RANS). Although large-eddy simulation (LES) models attract much interest, their applications are limited since it is computationally more expensive than RANS. For this reason, RANS models are widely used in urban flow and dispersion research. In the present study, the age of air is estimated based on RANS is applied.

One important note here is that; the numerical simulation of diffusion is sometimes inaccurate. This matter is due to two reasons: insufficient spatial resolution and the steep concentration gradients that exist within the same calculation domain. Upwind of a source, the concentration is almost zero, while in the regions close to the emission source; the concentration is at a maximum and decreases as the plume travels downwind the emission source. Thus, significant variations occur in the concentration values between adjacent cells, which lead to steep concentration gradients.

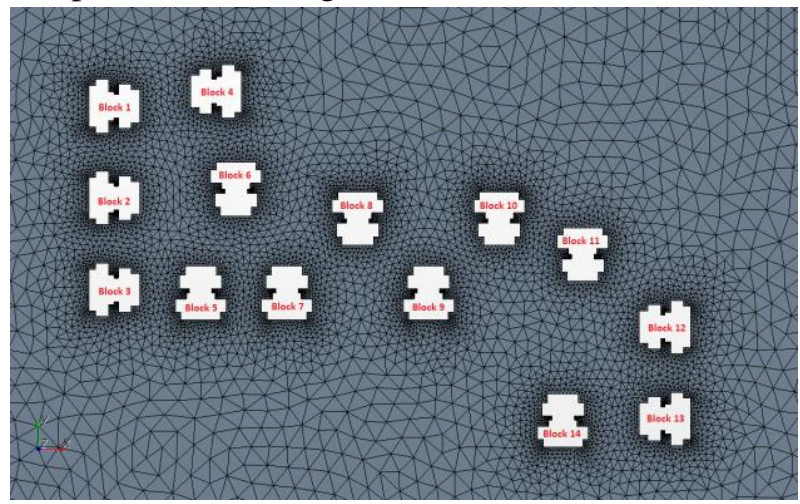

Fig. 4. The Mesh system for E-JUST campus

Wind flow characteristics in urban environments are different from those of enclosed domains due to the unsteadiness caused by fluctuations of the wind in both speed and 
Mahmoud Bady, Application of Age of Air of Indoor Environments as a Promising Index to....

direction. Accordingly; a considerable deviation between measured and calculated concentrations of air pollutants is expected. However, such deviation can be reduced if the CFD simulations parameters are selected carefully.

Table 1.

CFD simulation parameters with the applied boundary conditions

\begin{tabular}{|l|l|}
\hline Turbulence model & The standard $k$ - $\varepsilon$ model \\
\hline Differential schemes & $\begin{array}{l}\text { Convection term: Second-order upwind scheme } \\
\text { Diffusion term: Central difference scheme } \\
\text { Concentration: First order upwind scheme }\end{array}$ \\
\hline Inflow conditions & $u=u_{o}\left(\mathrm{z} / \mathrm{z}_{\mathrm{o}}\right)^{0.25}, u_{o}=1 \mathrm{~m} / \mathrm{s}, z_{o}=74.6 \mathrm{~m}, \theta=37^{\circ}$ \\
& $k=1.5(u \times I)^{2}, \varepsilon=\mathrm{C}_{\mu}^{1 / 2} \times k \times \frac{\partial u}{\partial z}$ \\
\hline Sides and sky & Free slip \\
\hline Walls and ground & Generalized Logarithmic law $(\mathrm{E}=9)$ \\
\hline
\end{tabular}

\section{Method of uniform pollutant generation rate}

As mentioned in the previous section, the age of air is estimated using passive pollutant technique, which means that; the pollutants do not influence the flow field. In order to avoid the problem of source location within the study domain, a uniform generation rate of the pollutant, which covers the whole volume of the domain is applied. Then, with the previously calculated flow field, the pollutant concentration is estimated through the solution of the scalar equation.

In this study, six cases are considered. The main variable in these cases was the pollutant generation domain. In each case, the study domain covers the space between the considered two blocks and extends to a height of $1.5 \mathrm{~m}$. Table 2 summarizes the six study cases. Figure 5 shows the homogeneous pollutant source for case 1, where the calculation domain covers the pedestrian level volume located between blocks 1 and 2. A uniform generation rate of $10^{-5} \mathrm{~kg} / \mathrm{m}^{3} / \mathrm{s}$ was applied in the six cases.

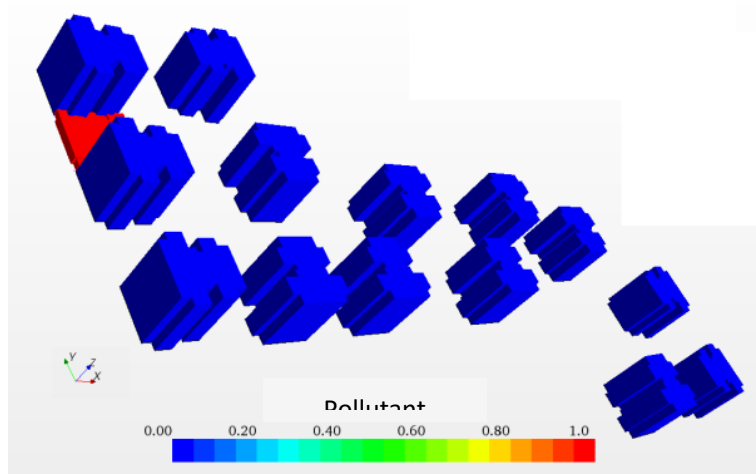

Fig. 5. A homogeneous pollutant source between blocks 1-2 (case 1)

\section{Results and discussion}

Figure 6 shows the wind flow field around E-JUST campus calculated at a height of $0.1 \mathrm{~m}$ above ground. The velocity values increase in the narrow voids between campus buildings, where it reaches a maximum value of $1.0 \mathrm{~m} / \mathrm{s}$. In the same time, Fig. 7 shows the estimated age of air within the study domain when a uniform pollutant source is between blocks 1 and 2 (case 1). 
Table 2.

Descriptions of the study cases

\begin{tabular}{|l|l|c|}
\hline & Domain location & Domain size $\left(\mathrm{m}^{3}\right)$ \\
\hline Case 1 & between blocks 1-2 & $18.0 \times 17.0 \times 2.0$ \\
\hline Case 2 & between blocks 2-3 & $18.0 \times 17.0 \times 2.0$ \\
\hline Case 3 & between blocks 3-5 & $14.0 \times 18.0 \times 2.0$ \\
\hline Case 4 & between blocks 7-9 & $39.5 \times 18.0 \times 2.0$ \\
\hline Case 5 & between blocks 8-10 & $36.0 \times 18.0 \times 2.0$ \\
\hline Case 6 & between blocks 5-7 & $15.5 \times 18.0 \times 2.0$ \\
\hline
\end{tabular}

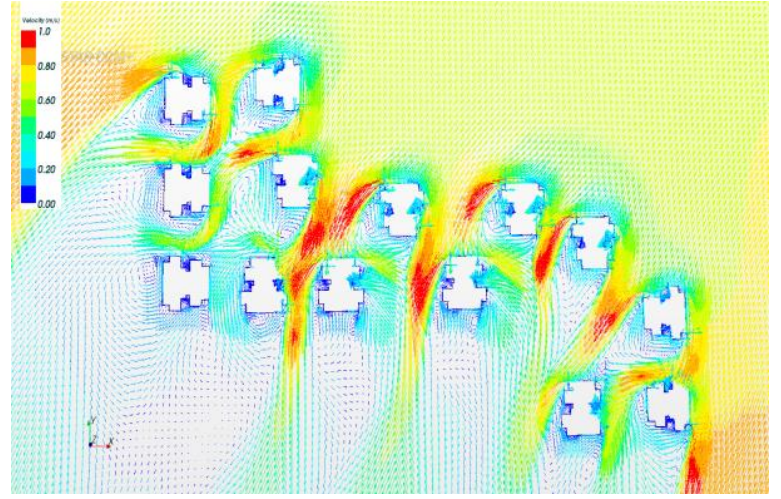

Fig. 6. Wind flow field around the blocks.

Similarly, Fig. 8 shows the case when the pollutant source exists between blocks 8 and 10 (case 5). Clearly, these figures indicate that the age of air increases in most narrow voids and canyons compared with other sites due to the low ventilation performance of the wind in these narrow domains.

Table 3 shows the estimated values of the average age of air for the six cases. The obtained values reflect excellent ventilation performance of the incident wind, where the maximum value of $\bar{\tau}_{p}$ in the six domains does not exceed 27.0 seconds.

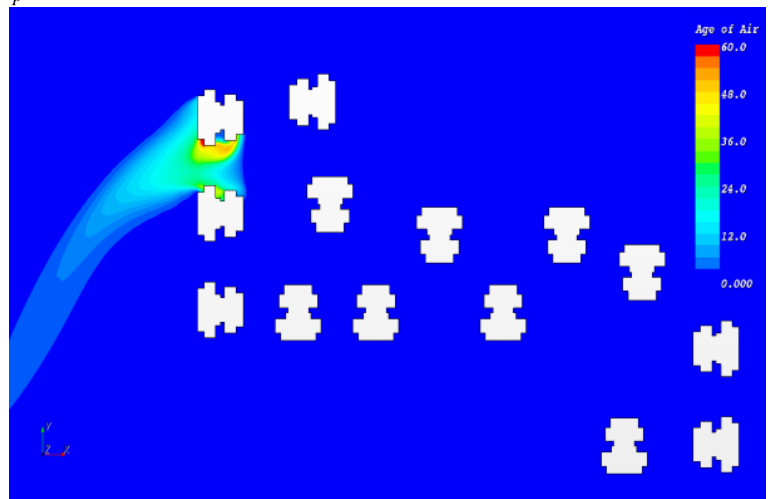

Fig. 7. Distribution of age of air for case 1

Since both PFR and the mean age of air are defined for the same domain and under the same conditions, they are expected to show similar performance since -in such case- they represent two sides of a coin. Accordingly, the greater the purging flow rate, the lower the mean age of air of the pollutant in the same domain. A small value of purging flow rate 
indicates that this domain is not well ventilated. Similarly, a higher value for the mean age of air is an indicator of poor removal efficiency of the pollutants by the incident wind. Figure 9 shows the performance of $\bar{\tau}_{p}$ against the PFR.

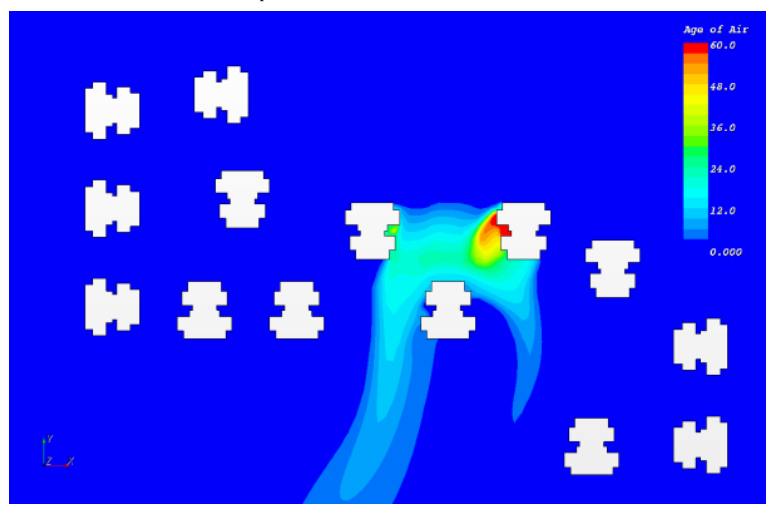

Fig. 8. Distribution of age of air for case 5.

Table 3.

The calculated age of air and $P F R$ for the six cases

\begin{tabular}{|c|c|c|c|}
\hline Case ID & $\begin{array}{c}c_{\text {avg }} \times 10^{3} \\
(\mathrm{~kg} / \mathrm{kg} \text { air })\end{array}$ & $\begin{array}{c}<\bar{\tau}_{p}> \\
(\mathrm{sec})\end{array}$ & $\begin{array}{c}P F R \\
\left(\mathrm{~m}^{3} / \mathrm{s}\right)\end{array}$ \\
\hline Case 1 & 0.279 & 24.0 & 21.3 \\
\hline Case 2 & 0.317 & 26.7 & 18.8 \\
\hline Case 3 & 0.266 & 20.0 & 18.1 \\
\hline Case 4 & 0.320 & 16.0 & 39.4 \\
\hline Case 5 & 0.239 & 15.2 & 51.0 \\
\hline Case 6 & 0.167 & 12.1 & 30.6 \\
\hline
\end{tabular}

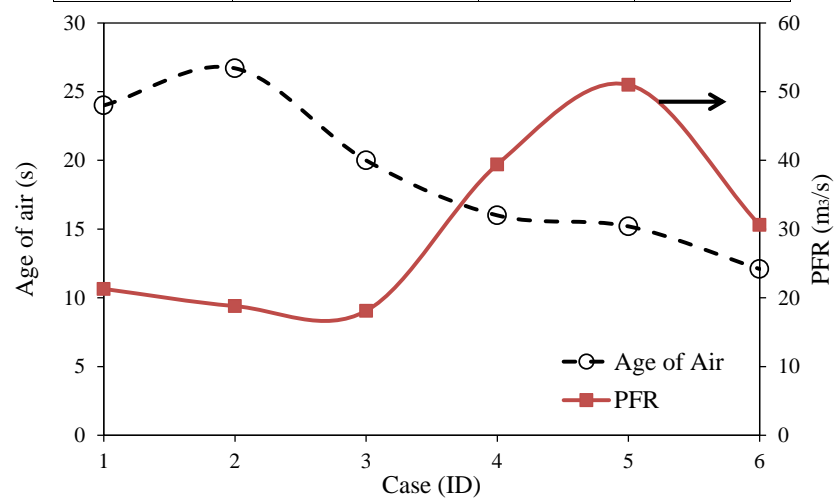

Fig. 9. Performance of $\bar{\tau}_{p}$ against the PFR.

The results of such example confirmed that the wind ventilation performance within a domain can be evaluated with the ventilation efficiency indices of indoor environments. The results also confirmed that ventilation efficiency indices can reflect the wind flow characteristics within urban areas very well. 
JES, Assiut University, Faculty of Engineering, Vol. 44, No. 3, May 2016, pp. 272 - 281

\section{Conclusions}

The present study investigates the applicability of age of air, which is one of the ventilation indices for indoor air, to evaluate the air quality of urban domains. CFD simulations were carried out to confirm the effectiveness of the index in reflecting the air quality of urban domains. An example for evaluating the air quality of urban domains in terms of the age of air was presented. The obtained results of the age of air index were compared with the values of another index which is the purging flow rate.

As a conclusion, the age of air index is an efficient tool for assessment of outdoor air quality as well as for indoor air. The results confirm that; ventilation efficiency indices can reflect the flow characteristics of urban domains very well.

\section{REFERENCES}

[1] Xiaomine X., Huang Z., and Wang J., Impact of building configuration on air quality in a street canyon, Atmospheric Environment, 39(25), 4519-4530, 2005.

[2] Tsai M. and Chen K., "Measurements and 3-D modelling of air pollutant dispersion in an urban street canyon, Atmospheric Environment, 38(35), 5911-5924, 2004.

[3] Baker C., and Hargreaves D., "Wind tunnel evaluation of a vehicle pollution dispersion model”. Journal of Wind Engineering and Industrial Aerodynamics, 89(2), 187-200, 2001.

[4] Mfula A., Kukadia V., Griffiths R., and Hall D., Wind tunnel modelling of urban building exposure to outdoor pollution, Atmospheric Environment, 39 (15), 2737-2745, 2005.

[5] Macdonald R., Griffiths R., and Hall D., "A comparison of results from scaled field and wind tunnel modelling of dispersion in arrays of obstacles". Atmospheric Environment, 32 (22), 3845-3862, 1998.

[6] Bady M., Kato S., and Huang H., "Towards the application of indoor ventilation efficiency Indices in evaluating the air quality of urban areas". Building and Environment, 43(12), 1991-2004, 2008.

[7] Kato S., Ito K., and Murakami S., "Analysis of visitation frequency through particle tracking method based on LES and model experiment". Indoor Air, 13 (2), 182-193, 2003.

[8] Sandberg M., Ventilation effectiveness and purging flow rate - A review, International Symposium on room air convection and ventilation effectiveness, 1-21, 1992.

[9] Huang H., Ryozo O., Kato S., and Jiang T., "CFD analysis of ventilation efficiency around an elevated highway using visitation frequency and purging flow rate". Journal of Wind and Structure, 9 (4), 297-313, 2006.

[10] Ferziger J., and Peric M., Computational methods for fluid dynamics, the second edition, Springer, Germany, 1997.

[11] Jian H., and Yuguo L., Age of air and air exchange efficiency in high-rise urban areas and its link to pollutant dilution, Atmospheric Environment 45, 5572-5585, 2011.

[12] Murakami S., Mochida A., and Hayashi Y., Modification of production terms in k- $\varepsilon$ model to remove overestimate of $\mathrm{k}$-value around the windward corner. The 10th Wind Engineering Symposium of Japan, 199-201 (in Japanese), 1998. 


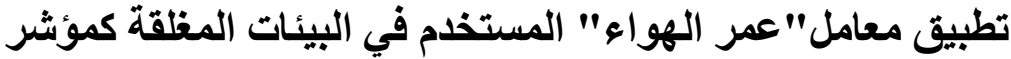

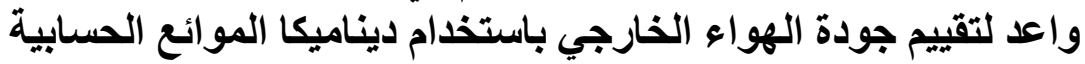 \\ الملخص العربى:}

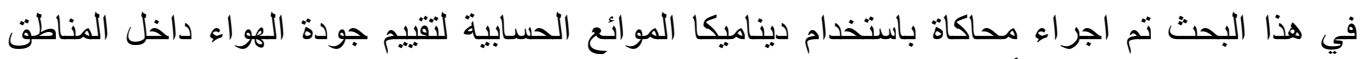

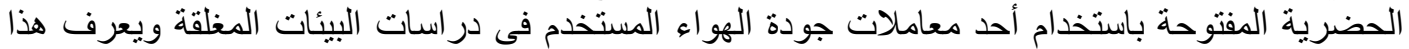

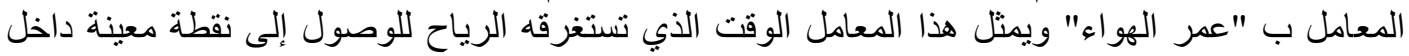

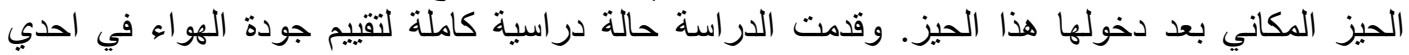

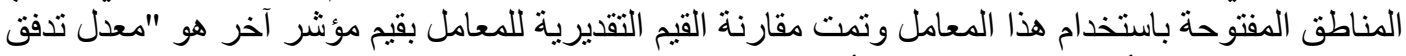

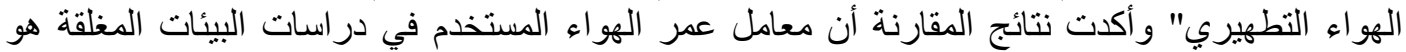
معامل و اعد جدا لتقييم جودة الهواء في المناطق المقار المفتوحة أيضنا. 